\title{
PRIVACIDADE E LIBERDADE DE EXPRESSÃO NA SOCIEDADE DA INFORMAÇÃO
}

\author{
PRIVACY AND FREEDOM OF EXPRESSION \\ IN THE INFORMATION SOCIETY
}

\author{
SILVANO GHISI ${ }^{1}$ \\ MARIA CRISTINA CERESER PEZZELLA²
}

\begin{abstract}
RESUMO: As tecnologias de informação e comunicações na Sociedade da Informação permitem capturar a presença humana em diversos ambientes, públicos ou privados, de modo clandestino e sem autorização, e na mesma medida possibilitam a reprodução e exposição das informações (imagens, sons, dados pessoais), muitas vezes transmudadas em criações e obras artísticas, a um universo infindável de pessoas e curiosos. Nesse contexto, o direito à privacidade e o direito à liberdade de expressão são postos em tensão direta e recebem novos elementos, já que as habilidades das tecnologias de informática e comunicação ampliam o espectro criativo assim como as vias de intrusão na vida particular dos indivíduos e violação da privacidade. O equilíbrio entre privacidade e liberdade de expressão perpassa, nesta conformação social, pelo direito à informação nos desdobramentos do direito de informar, de se informar e de ser informado, assim como por um juízo de sopesamento de viés utilitarista, e a análise de casos concretos permite ver que a privacidade vem sofrendo riscos crescentes de aniquilação.

PALAVRAS-CHAVE: Direitos Fundamentais; Sociedade da Informação; Privacidade; Liberdade de Expressão.
\end{abstract}

SUMMARY: The information and communications technologies in the information society allow capture human presence in different environments, public or private, clandestine and unauthorized manner and to the same extent possible the reproduction and display of information (images, sounds, personal data) often transmuted into artistic creations and works, an endless universe of people and curious. In this context, the right to privacy and the right to freedom of expression

Artigo recebido em 07.06.2014. Pareceres emitidos em 17.09.2014 e 15.10.2014.

Artigo aceito para publicação em 19.01.2015.

${ }^{1}$ Mestrando em Direitos Fundamentais pela Universidade do Oeste de Santa Catarina - UNOESC, Chapecó/SC. Especialista em Direito pela Escola da Magistratura do Paraná, Francisco Beltrão/PR. Pós-Graduado em Direito e Processo do Trabalho pela Faculdade de Direito de Francisco Beltrão, Francisco Beltrão/PR. silvanoghisi@gmail.com

2 Doutora em Direito pela Universidade Federal do Paraná UFPR. Mestre em Direito pela Universidade Federal do Rio Grande do Sul UFRGS. Professora do Programa de Pesquisa e Extensão e Pós-Graduação em Direito da Universidade do Oeste de Santa Catarina UNOESC, Chapecó/SC.crispezzella@uol.com.br 
are brought into direct tension and receive new elements, since the skills of computer and communication technologies extend the creative spectrum as well as the routes of intrusion into the private lives of individuals and violation privacy. The balance between privacy and freedom of expression pervades, this social form, the right to information in the unfolding of the right to inform, to inform and to be informed, as well as an assessment of proportionality utilitarian bias, and analysis of specific cases allows see that privacy is suffering increased risk of annihilation.

KEYWORDS: Fundamental Rights; The Information Society; Privacy; Freedom of Expression.

SUMÁRIO: Introdução; 1. Direitos à Privacidade e à Liberdade de Expressão; 2. Privacidade e Liberdade de Expressão na Sociedade da Informação; Considerações Finais; Referências.

CONTENTS: Introduction; 1. Rights to Privacy and Freedom of Expression; 2. Privacy and Freedom of Expression in the Information Society; Conclusory Remarks; References.

\section{INTRODUÇÃO}

Das liberdades reconhecidas ao indivíduo, pode-se respigar aquela de se reservar da percepção alheia, e aquela de se por em evidência a todos pela expressão de pensamento, mediante opiniões, atitudes e criações intelectuais e artísticas. Na primeira está o direito à privacidade, decorrente da matriz da liberdade, representando a autonomia do indivíduo para pôr-se a salvo do contato e intromissão alheia, buscando refúgio, isolamento e solidão, de modo a impedir o conhecimento por terceiros de fatos relacionados à sua vida particular. Na segunda o direito à liberdade de expressão, de pensar e criar, e de livremente levar ao conhecimento alheio os resultados do espírito sensível e inventivo humano, sem prévia censura ou limitações.

Na Sociedade da Informação, caracterizada pela efervescência e profusão de tecnologias de informática e comunicações, e por dispositivos tecnológicos variados, que possibilitam a captura e divulgação de imagens e dados pessoais, os direitos à privacidade e a liberdade de expressão recebem nova tônica.

Com este ímpeto, o presente estudo pretende identificar, inicialmente, estes dois direitos dentro das categorias dos direitos humanos e direitos fundamentais, em seguida delimitando-os e distinguindo de outros direitos próximos e conexos. A partir daí, com análise de casos concretos de situações somente possibilitadas pelas características e mecanismos da Sociedade da Informação, busca identificar violações e soluções no embate entre dois direitos essenciais para as sociedades modernas democráticas.

\section{DIREITOS À PRIVACIDADE E À LIBERDADE DE EXPRESSÃO}

Direitos humanos e direitos fundamentais são categorias próximas, porém não sinônimas. Admitem-se como direitos humanos aqueles a princípio de intuito universalista, atribuíveis aos seres humanos pelo simples fato de se 
tratarem de seres humanos ${ }^{3}$, válidos, aplicáveis e exigíveis além de qualquer fronteira espacial ou restrições de ordenamentos jurídicos, notadamente, ainda que não exclusivamente, expressados em instrumentos internacionais. Nesse passo, o diploma internacionalista de maior expressão acerca dos direitos humanos é a Declaração Universal dos Direitos Humanos da ONU de 1948.

Os direitos fundamentais, por seu turno, são aqueles a priori reconhecidos como direitos humanos e eleitos como valores fundamentais de uma determinada ordem jurídico-política, incorporados em ordenamentos jurídicos internos por uma matriz constitucional. Em outras palavras, os direitos fundamentais de um povo são os direitos humanos constitucionalmente assegurados, conforme explanado por Sarlet,

\begin{abstract}
embora sejam ambos os termos ('direitos humanos' e 'direitos fundamentais') comumente utilizados como sinônimos, a explicação corriqueira, e diga-se de passagem, procedente para a distinção é de que o termo 'direitos fundamentais' se aplica àqueles direitos do ser humano reconhecidos e positivados na esfera do direito constitucional positivo de determinado Estado, ao passo que a expressão 'direitos humanos' guardaria relação com os documentos de direito internacional, por referir-se àquelas posições jurídicas que se reconhecem ao ser humano como tal, independentemente de sua vinculação com determinada ordem constitucional, e que, portanto, aspiram à validade universal, para todos os povos e tempos, de tal sorte que revelam um inequívoco caráter supranacional (internacional) ${ }^{4}$.
\end{abstract}

Sem se olvidar das sérias discussões em torno da influência cultural e o relativismo no tocante aos direitos humanos, é a distinção acima discorrida entre direitos humanos e direitos fundamentais que se adota no presente estudo.

Fixadas estas premissas, cumpre investigar se a privacidade e a liberdade de expressão se enquadram como direitos fundamentais, sendo então pressuposto precedente encontrá-las entre os direitos humanos.

Analisando a Declaração Universal dos Direitos Humanos de 1948, tem-se o direito à privacidade no art. XII, ao dispor que "ninguém será sujeito a interferências na sua vida privada, na sua família, no seu lar ou na sua correspondência, nem a ataques à sua honra e reputação. Toda pessoa tem direito à proteção da lei contra tais interferências ou ataques". Por outro lado, o direito à liberdade de expressão está contido no art. XIX da mesma declaração, prevendo que "toda pessoa tem direito à liberdade de opinião e expressão; este direito inclui a liberdade de, sem interferência, ter opiniões e de procurar, receber e transmitir informações e ideias por quaisquer meios e independentemente de fronteiras".

${ }^{3}$ BOBBIO, Norberto. A Era dos Direitos. Tradução de Carlos Nelson Coutinho. Rio de Janeiro: Elsevier, 2004.

${ }^{4}$ SARLET, Ingo Wolfgang. A Eficácia dos Direitos Fundamentais. 9. ed., Porto Alegre: Livraria do Advogado, 2008. p. 31-32. 
$\mathrm{Na}$ linha antes fixada, portanto, a privacidade e liberdade de expressão consubstanciam-se em direitos humanos, e se não bastar para tanto vê-las na Declaração Universal dos Direitos Humanos de 1948, será possível também identificá-las nos art. XXII e XII da Declaração Universal Islâmica de 1982, respectivamente, e no art. 21 e 32, 1, da Carta Árabe dos Direitos Humanos de 2004, o que revela razoável consenso dos povos pelo reconhecimento da importância dos mesmos direitos, reafirmando seu caráter universalista.

Determinadas a privacidade e a liberdade de expressão como representações de direitos humanos, necessário então firmar a compreensão do que consiste cada qual, principiando pela privacidade.

Dentre as várias concepções sobre o tema, e que apresentam algumas variações, a privacidade pode ser compreendida como o direito que tem por objeto "os comportamentos e acontecimentos atinentes aos relacionamentos pessoais em geral, às relações comerciais e profissionais que o indivíduo não

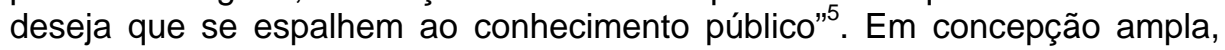
a privacidade consiste naquele conjunto de informações do indivíduo sobre as quais ele próprio tem o poder de manter sob seu controle, confidenciais, até que resolva comunicar a alguém, e a quem levar o conhecimento destas informações e sob quais condições, sem ser obrigado a efetuar tal revelação por meios legais ${ }^{6}$.

Notadamente que a privacidade tem importância se considerada com um direito de relação, na medida em que se só pode clamar por respeito à privacidade diante do estabelecimento de relações fáticas e jurídicas com outros indivíduos ou com a uma determinada comunidade em que se esteja inserido. Esta compreensão é referendada por Doneda ${ }^{7}$, para quem, o direito à privacidade ganhou relevo a partir do momento em que a pessoa humana passou a ser o centro dos ordenamentos jurídicos.

A privacidade experimentou um importante processo evolutivo, passando de um direito totalmente individual, refletido na forma do "direito de ser deixado só", , para um novo aspecto de direito adrede à realização da pessoa e desenvolvimento de sua personalidade. Todavia, o supracitado autor não

\footnotetext{
${ }^{5}$ MENDES, Gilmar; BRANCO, Paulo Gustavo Gonet. Curso de Direito Constitucional. 7. ed., São Paulo: Saraiva, 2011. p. 315.

${ }^{6}$ SILVA, José Afonso de. Curso de Direito Constitucional Positivo. 35. ed., São Paulo: Malheiros, 2012. p. 206.

${ }^{7}$ DONEDA, Danilo Cesar Maganhoto. Da Privacidade à Proteção de Dados Pessoais. Rio de Janeiro: Renovar, 2006. p. 8-9.

${ }^{8}$ De acordo com o escorço feito por Schreiber (2013, p. 135), o direito à privacidade tem como "marco inicial o artigo The Right to Privacy, publicado em 1890 na Harvard Law Review, revista jurídica da prestigiosa faculdade norteamericana. O artigo, escrito em coautoria pelos advogados Samuel Warren e Louis Brandeis, teria sido motivado pelo destaque exagerado, embora não difamatório, que os jornais de Boston reservavam à vida social da mulher de Samuel. Essa motivação explica o sentido essencialmente individualista que assumiu, no texto, o direito à privacidade, apresentando como um 'direito a ser deixado só' (right to bel et alone)".
} 
descarta que a privacidade mesmo hodiernamente continua ostentando traços individualistas oriundos de sua forma originária ${ }^{9}$.

Quase em simbiose com a privacidade está a intimidade, sendo na verdade um desdobramento da primeira, e assim merecendo distinção. Segundo Mendes e Branco, "o objeto do direito à intimidade seriam as conversações e os episódios ainda mais íntimos, envolvendo relações familiares e amizades mais próximas"10. Vieira vai além e afirma que a intimidade consiste em um aspecto mais profundo, pois "por corresponder à esfera mais interior do indivíduo, deve ser sempre mantida em segredo, inacessível e escondida, sendo de conhecimento apenas do próprio titular"11.

De toda forma, é consenso doutrinário que a privacidade configura uma aura de proteção, tendente a barrar a intromissão alheia, mais ampla que a intimidade.

Já a liberdade de expressão tem raízes no direito geral de liberdade, consubstanciando-se em uma conquista das sociedades modernas, antecedendo à própria ideia de Estado. Conforme Constant ${ }^{12}$, a liberdade é "para cada um o direito de não se submeter senão às leis, de não poder ser preso, nem detido, nem condenado, nem maltratado de nenhuma maneira, pelo efeito da vontade arbitrária de um ou de vários indivíduos". Silva, por sua vez, discorre que a liberdade "consiste na possibilidade de coordenação consciente dos meios necessários à realização da felicidade pessoal"13.

A toda evidência, a liberdade de expressão erige-se com um direito subjetivo dos indivíduos a partir da modernidade, ante a secularização e quebra da característica da religião em ser a única fonte legítima de conhecimento. A razão permitiu a cada indivíduo conhecer e produzir conhecimento, gerar e transmitir informações, dependendo da liberdade de expressão para o desenvolvimento dessa função. A ruptura com o discurso teológico estabelecedor de dogmas, deu origem a verdades questionáveis ${ }^{14}$, o que permitiu o franco desenvolvimento da liberdade de expressão.

A liberdade, portanto, confere autonomia, faculdades, prerrogativas, e escolhas. A liberdade de expressão é dotada destes mesmos aspectos, e de acordo com Meyer-Pflup "é intrínseca à natureza do homem expor suas ideias, opiniões, pensamentos, sensações e sentimentos e tentar convencer

\footnotetext{
${ }^{9}$ DONEDA, Idem, p. 8.

${ }^{10}$ MENDES e BRANCO, Ibidem.

${ }^{11}$ VIEIRA, Tatiana Malta. O Direito à Privacidade na Sociedade da Informação: efetividade desse direito fundamental diante dos avanços da tecnologia da informação. Porto Alegre: Sérgio Antônio Fabris, 2007. p. 36.

${ }^{12}$ CONSTANT, Benjamin. Da Liberdade dos Antigos Comparada à dos Modernos. Revista Filosofia Política, $\mathrm{n}^{\circ}$ 2, 1985. Disponível em: <http://caosmose.net/candido/unisinos/textos/benjamin.pdf>. Acesso em: 06 jun. 2014.

${ }^{13}$ SILVA, Idem, p. 233.

${ }^{14}$ FERNÁNDEZ, Antonio Aguilera. La Libertad de Expresión del Ciudadano y la Libertad de Prensa o Información: possibilidade y limites constitucionales. Granada, ES: Comares, 1990.
} 
os demais sobre a importância e veracidade deles"15. Daí porque, a princípio, o direito de manifestar o pensamento, de exprimir ideias e criações, deve ocorrer de forma livre, sem ameaças ou limitações jurídicas prévias.

Preciosa ao pensamento liberal, a liberdade de expressão, na sua conotação mais pura, pode ser apreendida do pensamento de Mill ${ }^{16}$ quando cogita que se toda a humanidade tivesse a mesma opinião sobre certa questão, menos uma pessoa, a humanidade seria tão injusta em impedir esta pessoa de expor seu ponto de vista, como seria injusta esta pessoa se tivesse poder de impedir que a humanidade toda opinasse. A peculiaridade do prejuízo resultante do cerceio da liberdade de expressão está em que comete um atentado à raça humana, tanto às gerações presentes quanto às futuras. A expressão da opinião não é um bem apenas pessoal cuja restrição pudesse acarretar algum prejuízo apenas aos indivíduos impedidos de manifestá-la; o mal causado pelo impedimento à liberdade de expressão atinge toda a humanidade.

Nessa conformação, a liberdade de expressão de pensamento e opinião encontraria rarefeitas restrições, e especialmente o Estado não poderia previamente determinar que opinião poderia ser manifestada e qual não poderia, sob pena de afronta à própria constituição do ser humano como sujeito autônomo e dotado de consciência livre. Apenas o prejuízo aos demais membros da sociedade pode funcionar como fator legitimador de limitações à livre manifestação de pensamento ${ }^{17}$.

A relevância da liberdade de expressão como direito reconhecido sem limitações estatais a priori é destacada por Farias, para quem a liberdade de externalizar pensamentos, opiniões, criações, etc., é uma características das sociedades democráticas, servindo de "termômetro do regime democrático"18, ou seja, quando mais se garanta a liberdade de expressão, mais democrática será a sociedade e seu sistema jurídico, pois representará menor tentativa de intromissão estatal no âmago dos indivíduos e em suas consciências.

Guerra, citando Dória, mesmo nominando de liberdade de pensamento, tenciona no particular que consiste no direito de "exprimir, por qualquer forma, o que se pense em ciência, religião, arte, ou o que for" ${ }^{19}$.

A relevância jurídica e social da liberdade de pensamento, ou de expressão, está na possibilidade de fazer com que outros conheçam o conteúdo dos pensamentos e opiniões do emissor, pois o pensamento enquanto involucrado

\footnotetext{
${ }^{15}$ MEYER-PFLUG, Samantha Ribeiro. Liberdade de Expressão e Discurso do Ódio. São Paulo: Revista dos Tribunais, 2009. p. 42.

${ }^{16}$ MILL, John Stuart. Sobre la Liberdad. Madrid: Alianza Editorial, 2004. p. 77.

${ }^{17}$ MILL, Idem, p. 127.

${ }^{18}$ FARIAS, Edilson Pereira de. Colisão de Direitos: a honra, a intimidade, a vida privada e a imagem versus a liberdade de expressão e informação. 3. ed., Porto Alegre: Sérgio Antônio Fabris, 2008. p. 143.

${ }^{19}$ GUERRA, Sidney Cesar Silva. A Liberdade de Imprensa e o Direito à Imagem. 2. ed., Rio de Janeiro: Renovar, 2004. p. 72.
} 
no íntimo do indivíduo não acarreta maiores problemas e importância. Silva, reportando-se a Pimenta Bueno, alterca que o homem não vive concentrado só em seu espírito, pois não é isolado, e sim um ser social ${ }^{20}$. Somente a vivência social, com atuação perante seus semelhantes é que dá tônica e importância à liberdade de expressão, pois ela pressupõe um interlocutor ou ao menos um ouvinte ou expectador.

Quando em foco a expressão do pensamento por meio da arte, assume a forma de liberdade de expressão artística, adrede a garantia da exteriorização do espírito humano sensível e inventivo. A importância da possibilidade de levar ao conhecimento alheio o resultado das criações intelectuais e artísticas humanas é ressaltada por Miranda, pois "não há liberdade de criação sem liberdade de expressão (...). E trata-se mesmo de uma liberdade de expressão qualificada, até porque a expressão pode ser de pensamento como de sentimentos e emoções" ${ }^{21}$.

Traçadas estas limitações conceituais sobre os direitos a privacidade e liberdade de expressão, é importante verificar, para o caso brasileiro, se também podem ser alocados na categoria dos direitos fundamentais. A conclusão é positiva, pois a Constituição Federal brasileira de 1988 incluiu no rol de direitos fundamentais a privacidade sob a denominação de "vida privada" ao lado e distinta da intimidade (art. $\left.5^{\circ}, X\right)$, ao passo que a liberdade de expressão está contida na fórmula mais ampla da liberdade de pensamento (art. $5^{\circ}, I V$ ), e na previsão específica de serem livres a expressão de atividades intelectuais, artísticas, científicas e de comunicação, que não dependerão de censura ou licença.

Nesse plano, o reconhecimento do caráter de direito fundamental à privacidade e liberdade de expressão ajusta-se a uma das propostas apresentadas por Alexy $^{22}$ no sentido de que normas de direitos fundamentais são aquelas que o próprio texto constitucional classifica como tal, isto é, insere em conjunto de disposições expressamente tituladas como direitos fundamentais.

\section{PRIVACIDADE E LIBERDADE DE EXPRESSÃO NA SOCIEDADE DA INFORMAÇÃO}

A realização da privacidade opera como uma barreira para o conhecimento e intromissão alheia quanto aos aspectos da vida pessoal, concedendo ao titular o direito de refúgio e isolamento contra qualquer tentativa de expectação ou auscultação pública. Outrossim, a liberdade de expressão pressupõe ausência de limitações, a autodeterminação sem sujeição a controle e censura para se expor o que se pensa, o que se imagina, o que se cria, a respeito de coisas e também de pessoas.

\footnotetext{
${ }^{20}$ SILVA, Idem, p. 241.

${ }^{21}$ MIRANDA, Jorge. Notas sobre Cultura, Constituição e Direitos Culturais. Coimbra: Almedina, 2006. p. 764.

${ }^{22}$ ALEXY, Robert. Teoria dos Direitos Fundamentais. Tradução: Virgílio Afonso da Silva. São Paulo: Malheiros, 2012. p. 66-69.
} 
Inevitável, assim, que por vezes são direitos que se põem em colisão, ocorrência fortemente ascendida na Sociedade da Informação, ou sociedade informacional como prefere Castells ${ }^{23}$. Na Sociedade da Informação, como o próprio nome que lhe define, a informação é o pressuposto de existência, e o fluxo, a transmissão dessa informação, é o fator de sua sustentabilidade. A informação, segundo Laborit apud Lojkine, "não é nem massa nem energia (...) em si, ela é imaterial, posto que representa 'este algo que faz com que o todo não seja apenas a soma das partes'”24. As tecnologias, por sua vez, permitem conservar este conhecimento e empregá-lo na transformação do mundo e na geração de outros conhecimentos.

$\mathrm{Na}$ Sociedade da Informação o universo natural transmuda-se na informação sobre ele, na conservação do dado ou conceito resultante da inflexão do sujeito sobre o objeto cognoscível. Nessa nova conformação de sociedade, o ser humano consubstancia-se na informação daquilo que dele se faz, desaguando numa sociedade da classificação, segundo compõe Rodotà $^{25}$. Assim, tanto quanto as relações sociais pressupõem a informação para se moldarem, os indivíduos, na Sociedade da Informação, se organizam a partir daquilo que são em virtude das informações sobre sua condição humana e social.

Algumas características da Sociedade da Informação são dignas de nota para melhor compreendê-la. A primeira das nuanças dessa moldagem social é a de que a informação é sua matéria prima, e as tecnologias evoluem adrede a propiciar a apropriação e uso da informação pelo ser humano.

Como segunda característica está a profícua penetrabilidade, visto que a informação é elemento indissociável de toda ação humana, de sorte que são autopoieticamente afetadas por cada nova tecnologia. Ou seja, o comportamento apresentado pela sociedade ao evidenciamento de novas tecnologias não é operado como um revide, mas refulge como um reflexo que já conta com, senão alterações, ao menos as irritações provocadas pela integração daquelas tecnologias. Por isso que o reflexo social às novas tecnologias é um fenômeno autroproduzido, uma autopoiésis ${ }^{26}$, pois que não é um reflexo aportado em estribos pretéritos à consideração das tecnologias, mas já carrega, a favor ou contra, a perturbação daquelas presenciada.

Significa, também, que, a partir da admoestação das novas tecnologias, e o reflexo da sociedade, elas são incorporadas, integradas, revolvidas e ascendem como elemento do próprio sistema social. No dizer de Decol,

\footnotetext{
${ }^{23}$ CASTELLS, Manuel. A Sociedade em Rede. A era da informação: economia, sociedade e cultura. Tradução de Roneide Venâncio Majer. 7. ed., São Paulo: Paz e Terra, 1999. p. 57-60.

${ }^{24}$ LOJKINE, Jean. A Revolução Informacional. Tradução de José Paulo Netto. 3. ed., São Paulo: Cortez, 2002. p. 113.

${ }^{25}$ RODOTÀ, Stefano. A Vida na Sociedade da Vigilância: a privacidade hoje. Tradução: Danilo Doneda e Luciana Cabral Doneda. Rio de Janeiro: Renovar, 2008. p. 111-112.

${ }^{26}$ LUHMANN apud NEVES, Clarissa Baeta; SAMIOS, Eva Machado Barbosa (Orgs.) Niklas Luhmann: a nova teoria dos sistemas. Porto Alegre: UFRGS, Goethe-Institut/ICBA, 1997. p. 25-26.
} 
“(..) uma vez estabelecida, uma tecnologia ganha vida própria"27. Assim, a sociedade já é diferente do que antes da tecnologia a ela integrada, e em razão desta integração, galgou outro patamar (não melhor, nem pior; diferencial), o que torna impossível, diante das ramificações e interdependências que estendeu com a nova tecnologia integrada, regredir ao estágio anterior. Pelo mesmo fundamento, tudo que daí passar a autoproduzir levará, evidentemente, características da integração tecnológica ocorrida, em razão do efeito ressonante a todo o sistema social. Em contrapartida, toda nova aderência de tecnologia dar-se-á matizada pela também perturbação do sistema social ao fenômeno tecnológico, numa vertente cíclica que é a alimentação, o revigoramento, a evolução e o fechamento do sistema social.

Assim operam as tecnologias de informática e telemática, que perpetram a sociedade da informação. Foram integradas, agrediram a sociedade e por ela foram irritadas. Nesse processo cada qual absorveu ao outro, de forma que se fechou novamente o sistema social. Destarte, novas relações, novos conceitos, diferentes associações foram modeladas para o sistema social e as tecnologias, tornando a sociedade dependente destas formações, de tal sorte que o retorno ao estágio anterior às tecnologias de informática e telemática já não é mais praticável sem a desestruturação do sistema social corrente. Ou seja, as tecnologias possuem, também, um papel de co-autores sociais ${ }^{28}$.

Outra característica da Sociedade da Informação é sua flexibilidade, já que torna facilitada a reorganização, e a factível capacidade de redefinição, ressignificação. A interação de tecnologias é outra característica, pois se observa o contínuo processo de diálogo entre áreas do conhecimento e tecnologias, com integração de elementos de eletrônica, telecomunicações, biologia e robótica.

Por fim, não há se falar em Sociedade da Informação, com a velocidade que se experimenta, sem reconhecer a característica sobranceira da lógica de redes, isto é, aparato essencial que permite a produção, compartilhamento e disseminação da informação, e ao mesmo tempo, no despertar de tecnologias para o trato e uso da informação.

Como descrevem Briggs e Burke, a Sociedade da Informação passou a unir um grupo de aspectos até então fragilmente ligados, isto é, conhecimento, notícias, literatura, entretenimento, que fluem, transitam e se compartilhar por diferentes meios e materiais midiáticos (papel, tinta, cine, radio, televisão e computadores ${ }^{29}$. Nos anos de 1960 um fator adicional conferiu maior força a Sociedade da Informação, quando se passou a tratar como dados, as mensagens criadas e transmitidas, públicas e privadas, verbais e visuais. Essa percepção da manipulação de dados derivou em informação que se

\footnotetext{
${ }^{27}$ DECOL, René Daniel. Era da Informação: sociedade, mito e tecnologia. [s.I.]: Cebrap, 2005. p. 5.

${ }_{28}^{28}$ DECOL, Ibidem.

${ }^{29}$ BRIGGS, Asa; BURKE, Peter. De Gutenberg a Internet: uma historia social de los medios de comunicación. Madrid: Santillana, 2002. p. 292.
} 
podia transmitir, colecionar e guardar, independentemente de sua origem, sendo as tecnologias eletrônicas e informáticas o modo mais efetivo de obter este resultado.

Nesse cenário, surge espinhosa preocupação, uma vez que as tecnologias de informação, informática e comunicação - cada vez mais rápidas e vorazes, mais acessíveis e integralizadas aos afazeres cotidianos da vida comum, a exemplo de celulares, tablets, redes de comunicação de alta velocidade, transmissão eletrônica em tempo real - criam um ambiente em que cada indivíduo é ao mesmo tempo vigilante e vigiado de todos e por todos.

Não se pode negar, então, que os mecanismos tecnológicos e comunicacionais da Sociedade da Informação tornam fértil o campo para o exercício da liberdade de expressão, inclusive para a expressão artística, já que conferem facilidades para a pesquisa, a criação e divulgação das obras e seus autores.

O aspecto diferencial consiste em que a manifestação de pensamento e opinião pode ser levado a um contingente indeterminado de pessoas em reduzido espaço de tempo (minutos ou segundos), sem gastos, não se dependendo de uma fonte de produção ou geração da informação formatada (gráfica, editora, produtora de áudio e vídeo, etc.). Antes do advento das tecnologias de informática e comunicações, em especial da Internet, a manifestação de pensamento se perfectibilizava por escritos em papel, vídeos e áudios, ou pronunciamentos em tempo real pelo emissor a um determinado público, circunstâncias que geravam considerável custo e uma gama bastante inferior de indivíduos atingidos pela comunicação.

Basta exemplificar que se existisse a intenção de divulgar um manifesto escrito contra determinada política governamental, o indivíduo interessado precisaria submeter a impressão em uma gráfica, ainda que artesanal, além de disseminar o impresso mediante distribuição pública, envio pelo correio, afixação em locais e visibilidade, etc. Além disso, o âmbito de indivíduo atingido ficaria sobremodo restrito à localidade do indivíduo emissor e aos demais dele já conhecidos ou com quem tinha contato prévio, dependendo de eventuais ações destes na reprodução do conteúdo e transmissão ao outros grupos.

A união de tecnologias de informática e comunicações desfez estas barreiras, tornando cada indivíduo uma fonte de produção e distribuição de conteúdos, eliminando a necessidade de intermediários na geração e formatação de manifestações de pensamento e opinião, além de ampliar indefinidamente o contingente de pessoas receptoras destas comunicações. Conforme expõe Lèvy, os novos modelos de comunicação e de acesso à informação são definidos pelo caráter diferenciado e personalizável, pela reciprocidade e um estilo de navegação hipertextual, isto é, formado por nós interligados por inúmeras conexões ${ }^{30}$.

${ }^{30}$ LÉVY, Pierre. Cibercultura. São Paulo: 34, 1999. p. 193. 
Estas tecnologias permitiram que a geração, reprodução e transmissão de conteúdos, a partir de uma rede de participação global, tornou uma tecnologia de massa, ampliando significativamente o número de atores e interlocutores neste ambiente, seja na produção de conteúdos (informações) seja como sujeitos receptores, entretanto aqui dotados da facilitada capacidade de armazenar e disseminar a outros a informação recebida, ante as habilitações permitidas pelos dispositivos tecnológicos e softwares. Com efeito, a possibilidade de manifestação e de obter informações nesse aparato da Sociedade da Informação não ficou restrita a uma elite, econômica ou intelectual, consubstanciando-se em um meio de massas, o que foi essencial para a pujança e lastreamento nos mais variados níveis da vivência humana e nas relações interpessoais, sociais e jurídicas ${ }^{31}$.

Em outras palavras, qualquer sujeito que esteja dotado de um dispositivo tecnológico capaz de captar a presença de outros, pode registrar e reproduzi-la de forma instantânea para um contingente indeterminado de pessoas, sem qualquer autorização prévia de tal divulgação, assim com utilizar estas captações na criação de qualquer conteúdo, inclusive de cunho artístico, e posteriormente divulgá-lo, sem qualquer consentimento ou autorização da pessoa cuja imagem ou dados foram captados.

Destarte, as tecnologias de informática e comunicação propiciam a captação da presença humana e sua reprodução pelos diversos ambientes, podendo recair em imagens, sons e dados pessoais, que são aspectos relevantes do direito à privacidade, merecem prudência. Por outro lado, a limitação prévia da possibilidade de coleta destes dados, e sua produção e disseminação como forma de manifestação de pensamento, deve ser conduzida com cautela, ante o risco de constituir ação antidemocrática, censuradora e violadora de liberdades.

O fator que dá maior tom à preocupação em torno da tensão entre liberdade de expressão e privacidade, na Sociedade da Informação, consiste no fato de que as tecnologias permitem a eternização dos pensamentos e opiniões manifestados, sua posse por uma infinidade de pessoas, e a instantânea ou posterior reverberação, reprodução, ampliando significativamente o universo de pessoas a que podem chegar ao conhecimento daquelas informações e, consequentemente, que passam a conhecer de fatos considerados secretos pelo indivíduo de quem as informações ou opiniões se referem.

Nota-se que a publicidade é o aspecto determinante do direito à liberdade de manifestação de pensamento e opinião, pois precisa ter visibilidade de modo a tornar-se apta ao conhecimento alheio, e a privacidade é o obstáculo mais firme contra a publicidade de fatos inerentes à vivência pessoal de cada indivíduo, o que justificou a proteção na forma de direito fundamental na Constituição Federal de 1988. De acordo com Pereira,

\footnotetext{
${ }^{31}$ BRIGGS e BURKE, Idem, p. 292.
} 
Ao preservar, de indébita intromissão, a intimidade e a vida privada dos cidadãos, quis o texto constitucional assegurar a cada um, na sociedade, o direito de não ver tornados públicos fatos que só o titular do direito pode ser juiz da oportunidade de sua divulgação, se e quando a sua publicidade não venha a expô-lo a incômodos ou constrangimentos, destarte garantindo-se, a cada um, o direito de não ter sua vida privada devassada, via da publicidade de fatos de sua intimidade, feita por meio de fotografias, filmes ou textos escritos ${ }^{32}$.

O embate entre liberdade de manifestação de pensamento e privacidade é candente e corriqueiro na Sociedade da Informação, e a análise de casos concretos fornece subsídios valiosos ao tema posto em discussão.

Um primeiro caso providencial nesta discussão, enfocando a imagem pessoal, que notadamente é um conteúdo de relevo do conjunto geral da privacidade ${ }^{33}$, é o da exposição artística "The Neighbors" (os vizinhos), ocorrida em Nova York, EUA, consistente em fotografias captadas clandestinamente de moradores de um prédio, a partir da janela do apartamento do autor da exposição, o fotógrafo Arne Svenson. Entre as fotografias estão pessoas comuns deitadas, se alimentando, escoradas na janela, fazendo serviços domésticos, e até mesmo de roupas íntimas.

O fotógrafo em questão foi alvo de ação judicial por alguns moradores sob a alegação de violação da privacidade e risco à segurança de crianças, contudo a Suprema Corte de Nova York decidiu, em agosto/2013, que as fotografias poderiam ser exibidas porque se consubstanciam em arte, e "Arte é liberdade de expressão e, portanto, garantida pela Primeira Emenda [da Constituição dos EUA]"34.

Circunstância diversa, mas que também envolve a exposição de fatos da vida particular, entretanto aqui enfocando pessoas de maior expressão pública (pessoas famosas), consiste na controvérsia sobre a licitude da publicação de biografias não autorizadas. Caso emblemático envolveu o cantor Roberto Carlos, quando publicada sua biografia não autorizada. Em 2007 o cantor ingressou com ação judicial em face dos autores da obra, buscando impedir a distribuição e venda, sob a alegação de invasão de privacidade, pedido que foi acolhido e confirmado pelo Tribunal de Justiça do Rio de Janeiro ${ }^{35}$.

Outro caso julgado por aquele mesmo tribunal, enfocando o mérito da publicação de biografias não autorizadas, reconheceu a ofensa, entre outros, ao direito de privacidade:

\footnotetext{
${ }^{32}$ PEREIRA, Áurea Pimentel. Estudos Constitucionais. São Paulo: Renovar, 2011. p. 73.

${ }^{33}$ Segundo Silva (2012, p. 206), "a esfera da inviolabilidade, assim, é ampla, 'abrange o modo de vida doméstica, nas relações afetivas em geral, fatos, hábitos, locais, nome, imagem, pensamentos e segredos, e, bem assim, as origens e planos futuros do indivíduo".

34 Disponível em: <http://www1.folha.uol.com.br/ilustrada/2013/09/1337626-fotografo-ganha-najustica-o-direito-de-exibir-fotos-intimas-de-vizinhos-em-nova-york.shtml>. Acesso em: 06 jun. 2014.

35 Disponível em: <http://www.conjur.com.br/2009-mar-10/biografia-roberto-carlos-nao-publicadadecide-tj-rj>. Acesso em: 06 jun. 2014.
} 
OBRA INTELECTUAL DIREITO DA PERSONALIDADE. GARANTIA CONSTITUCIONAL. DIREITO A IMAGEM. VIOLAÇÃO DO DIREITO. DANO MATERIAL. OBRIGAÇÃO DE INDENIZ̧AR. EMBARGOS INFRINGENTES. DESPROVIMENTO. DIREITOS DA PERSONALIDADE. Publicação Não Autorizada de Biografia de Pessoa Falecida. Direito dos Herdeiros. A biografia de uma pessoa relata fatos relacionados com o seu nome, imagem, intimidade e outros aspectos vinculados aos direitos da personalidade. Se é certo que esses direitos extinguem-se com a morte do seu titular, certo é também que a personalidade das pessoas famosas projeta efeitos jurídicos para além da morte e que afetam os seus sucessores. Os efeitos econômicos assim projetados incorporam-se ao patrimônio dos herdeiros do falecido e só a eles cabe a faculdade de explorá-los ou não comercialmente. Dessa forma, os sucessores de pessoas famosas passam a ter, por direito próprio, legitimidade para pleitearem indenização em juízo. Terceiros não podem se apropriar desses direitos e publicar obra biográfica sem a autorização dos herdeiros, por mais erudita que seja a obra e nobres os seus propósitos. O exercício da livre manifestação do pensamento, da expressão intelectual e da profissão não autorizam a apropriação dos direitos de outrem para fins comerciais e de lucro, por se encontrar isso fora do direito de informar. $O$ dano patrimonial decorre do locupletamento da popularidade do biografado comercialmente explorada, sem a autorização de quem de direito, ou sem Ihe dar a devida participação nos lucros. O arbitramento da indenização, pelo dano material, em valor correspondente a $5 \%$ (cinco por cento) do preço de capa de cada exemplar é medida compatível, justa e ponderada e que melhor se ajusta ao objeto da lide. Desprovimento do recurso ${ }^{36}$ [grifou-se].

Nesse plano, cabe destacar o Projeto de Lei n 393/2011, em tramitação na Câmara dos Deputados, cujo intuito geral é a de "ampliar a liberdade de expressão, informação e acesso à cultura" por meio da permissão de "divulgação de imagens e informações biográficas sobre pessoas de notoriedade pública, cuja trajetória pessoal tenha dimensão pública ou cuja vida esteja inserida em acontecimentos de interesse da coletividade". A justificativa do autor do projeto, Dep. Newton Lima, que pretende incluir um $\S 2^{\circ}$, ao art. 20 do Código Civil vigente, é a de que:

As personalidades públicas, entendidas como políticos, esportistas, artistas, entre outros, são pessoas cujas trajetórias profissionais e pessoais confundem-se e servem de paradigma para toda a sociedade. Por sua posição de destaque em relação aos demais cidadãos, as pessoas notoriamente conhecidas verificam que suas condutas, sejam pessoais, sejam decorrentes do exercício da profissão, são norteadoras das decisões de diversos seguimentos sociais, os quais valorizam as escolhas pessoais realizadas por tais personalidades públicas, muitas vezes até reproduzindo-as.

\footnotetext{
${ }^{36}$ TJRJ, 2 2a Câmara Cível, Processo 0000823-11.1996.8.19.0001 (2002.005.00058), Des. Sérgio Cavalieri Filho, j. 15.05.2002. Disponível em: <http://www.tjrj.jus.br>. Acesso em: 20 out. 2013.
} 
Os casos acima revelam um intenso embate entre dois direitos fundamentais, de um lado o direito à liberdade de expressão artística, e de outro o direito à privacidade. Sua resolução faz-se a partir da aplicação do princípio da proporcionalidade, em mente as premissas da necessidade, utilidade e proporcionalidade em sentido estrito discorridas por Alexy ${ }^{37}$. A premissa, no ponto, é o sopesamento, ou seja, desvelar em cada caso concreto qual direito envolvido pode e deve ser infligido um sacrifício maior que a outro, tendo em mente sua importância para o sistema jurídico abstratamente considerado e também, especialmente, para os indivíduos e os fatos envolvidos no caso concreto.

No tocante ao conflito entre liberdade de manifestação e privacidade, o desafio é desvelar qual deve prevalecer e qual deve ser sacrificado de modo que, apenas no caso em exame, abra espaço para a vazão atuante do direito privilegiado. Todavia, o direito desprezado, que na análise mereceu menos valor, segue atuado como limite de desenvolvimento do direito prevalente, evitando, assim, o exercício abusivo de direito.

Mas para além a colisão entre estes dois importantes direitos fundamentais, os casos revelam a fragilidade da vida privada na Sociedade da Informação, onde tecnologias podem captar a existência de pessoas, às ocultas, e criações pretensamente artísticas podem levá-las a visibilidade e exposição a um contingente indeterminado de curiosos.

Nesse plano, a consideração sobre o direito à informação oferece relevantes elementos ao embate entre privacidade e liberdade de expressão. No ordenamento jurídico brasileiro o direito à informação vem primordialmente capitulado no art. 50, XIV, da Constituição Federal de 1988, estabelecendo ser "assegurado a todos o acesso à informação e resguardado o sigilo da fonte, quando necessário ao exercício profissional".

De acordo com Meyer-Pflup, o direito à informação "consiste no direito de se obter informações bem como o direito de informar" ${ }^{38}$. A citada jurista identifica no direito de informação duas nuanças, a primeira como direito de se informar e a segunda como direito de informar. Indo além, Farias visualiza um desdobramento a mais, consistente no direito de ser informado ${ }^{39}$. Para este autor, o direito à informação reproduz-se nos direitos de informar, informar-se e ser informado ${ }^{40}$. O primeiro consistente do direito de produzir e levar informações às pessoas, o segundo no direito de buscar informações (acesso à informação), e o terceiro no direito de receber informações.

O cerne da questão, à luz do direito à informação, está em identificar a necessidade e utilidade de determinada informação para a vida das pessoas, e como estas justificativas atuam sobre a garantia da liberdade de expressão

\footnotetext{
${ }^{37}$ ALEXY, Idem, p. 117.

${ }^{38}$ MEYER-PFLUP, Idem, p. 42.

${ }^{39}$ FARIAS, Idem, p. 162-163.

${ }^{40}$ FARIAS, Ibidem.
} 
e a proteção à privacidade. Não há se negar que a concepção utilitarista dos direitos em foco contribui para o desenrolar do problema.

Como anotam Mendes e Branco, "verifica-se a tendência de tomar como justificável a intrusão sobre a vida privada de alguém quando houver relevância pública na notícia que expõe o indivíduo"41. Ou seja, o conhecimento de determinada informação, ou nos casos acima relatados a expectação das fotografias daquelas pessoas comuns em suas residências, ou os relatos das biografias não autorizadas, deve ser importante para decisões da vida dos espectadores que impliquem na fruição ou facilitação de fruição de direitos que tragam efetiva vantagem à sua vida e aos seus destinos, sendo necessário mais que o mero deleite por saber da vida alheia.

A pergunta que se deve fazer é o que o conhecimento daqueles fatos a priori atinentes a aspectos particulares da vida de outras pessoas trará de legitimamente vantajoso, no sentido do exercício de direitos, da emancipação, e do empoderamento ${ }^{42}$, para quem vier a conhecer dessa informação.

Transparece que na mesma medida o direito de informar perpassa pelo filtro da utilidade e, ainda, da boa-fé, pois é essencial apreender o objetivo em divulgar determinada informação, sobremodo para buscar identificar se sob o manto do direito de informar não se escondem intenções fúteis ou torpes, como o mero intuito de expor e denegrir a imagem alheia, ou ainda interesses puramente econômicos ocultos sob o manto da expressão artística.

O caso das biografias não autorizadas dá azo à percepção do cunho estritamente econômico da produção "artística", pois a menção de a obra não ter sido autorizada pelo sujeito de quem se fala desperta ávida curiosidade alheia, porque podem ali supostamente constar segredos que não seriam revelados espontaneamente caso se tratasse de uma biografia precedida de autorização da personagem sobre quem se escreve. Bem a esse modo, relata Schreiber a visão do historiador José Murilo de Carvalho, entusiasta das biografias não autorizadas, ao admitir que: "quando vejo na capa de um livro 'biografia autorizada', eu não abro o livro. Não tem valor: a biografia autorizada é uma fraude porque está dizendo que o biógrafo está escrevendo aquilo que o biografado gostaria que ele escrevesse" ${ }^{43}$.

A motivação estritamente econômica no particular consiste em, com o apelo de tratar-se de uma escrita não autorizada, conter algo proibido e que quem se dispuser a ser leitor saberá de segredos não divulgados publicamente,

\footnotetext{
${ }^{41}$ MENDES e BRANCO, Idem, 320-321.

${ }^{42}$ Adota-se empoderamento no sentido preconizado por Schiavo e Moreira (2005, p. 59) que "implica, essencialmente, a obtenção de informações adequadas, um processo de reflexão e tomada de consciência quando à sua condição atual, uma clara formulação de mudanças desejadas e da condição a ser construída. A estas variáveis deve somar-se uma mudança de atitude que impulsione a pessoa, grupo ou instituição, para a ação prática, metódica e sistemática, no sentido dos objetivos e metas traçadas, abandonando-se a antiga postura meramente reativa ou receptiva".

${ }^{43}$ SCHREIBER, Anderson. Direitos da Personalidade. 2. ed., São Paulo: Atlas, 2013. p. 149.
} 
o que certamente funciona como chamariz à venda da obra literária da espécie, pois a biografia se apresentará como algo precioso para quem resolver adquiri-la, o que lhe agrega valor comercial considerável.

Em defesa do supracitado Projeto de Lei $n^{\circ} 393 / 2011$, seu autor alterca que o conhecimento da história é um direito de todos, o que certamente traduziria o direito de ser informado e de informar-se, e contá-la é um direito de cada um, refletindo o direito de informar. O exercício destes direitos, segundo o autor do projeto, não se sujeitaria à censura ou licença do Estado, tampouco dos personagens envolvidos na biografia relatada.

Todavia, retornando ao caso envolvendo o cantor Roberto Carlos, o interesse do público pela biografia não autorizada sobre si não esteve respaldado no direito de se informar a respeito das contribuições do artista para a música popular brasileira, para a cultura nacional, etc. O que tornou a biografia procurada foi o fato de nela constar o relato de que o cantor possui prótese em um dos membros inferiores, vindo a ser jocosamente chamada "perna-de-pau", um aspecto íntimo e irrelevante para sua atuação profissional e pública, mas ainda assim o que despertou a curiosidade alheia, o que é comprovado pelo número de artigos e fóruns encontrados na Internet sobre o assunto ${ }^{44}$.

A partir da análise das situações acima, enfim, verifica-se que a privacidade está sob severo risco na Sociedade da Informação, e muitas vezes o exercício da liberdade de expressão é o fator mais agressor e danoso, justamente porque a fundo representa o desenvolvimento de outros interesses além dos direitos de informar, ser informado e se informar que compõe o núcleo do direito à informação. $O$ desvirtuamento ou abuso da liberdade de manifestação de pensamento e opinião se traduzem, nos mais das vezes, como ações invasivas à privacidade dos indivíduos, pelo simples deleite pessoal em revelar o alheio e oculto, ou pelos interesses comerciais em torno da notícia e da arte.

Ante esta percepção, estudos têm levado a se reconhecer uma nova concepção de privacidade, sobremodo quando em foco as informações pessoais. Nessa raia, Doneda defende "uma transformação na definição do direito à privacidade, do 'direito de ser deixado em paz' para o 'direito a controlar o uso que outros fazem das informações que me digam respeito","45.

No mesmo sentido pondera Rodotà que em um momento histórico em que os dados pessoais são facilmente circuláveis, a privacidade desloca-se da clássica fórmula do direito de estar só (de ser deixado em paz) para o direito de o próprio indivíduo controlar o uso e destinação das informações a seu respeito ${ }^{46}$. A mudança do enfrentamento da privacidade passa do sigilo

\footnotetext{
${ }^{44}$ Cf., consulta realizada do sistema de buscas on-line Google.com (www.google.com), em 06 jun. 2014.

${ }^{45}$ DONEDA, Danilo Cesar Maganhoto. Considerações Iniciais sobre Bancos de Dados Informatizados e o Direito à Privacidade. In: TEPEDINO, Gustavo (org.) Problemas de Direito Civil-constitucional. Rio de Janeiro: Renovar, 2000, p. 120.

${ }^{46}$ RODOTÀ, Idem, p. 24.
} 
para o controle, especialmente porque hodiernamente é muito difícil separar aquelas informações que o indivíduo estaria disposto a revelar e quais não. E tanto decorre da percepção de que "até informações aparentemente mais inócuas podem, se integradas a outras, provocar dano ao interessado"47.

A visão dos autores supracitados tem seu valor e é relevante na Sociedade da Informação, porquanto dados pessoais circuláveis fazem parte do cotidiano humano, e o controle de seu uso, das criações artísticas, das escolhas e decisões políticas que deles se fazem, perpassam pela tensão entre privacidade e liberdade de expressão, mediadas pelo direito à informação.

A coleta e reprodução desautorizadas de informações da vida privada, mesmo que sob o pretexto de criação artística, fere o direito a privacidade daquele sobre quem se referem tais dados, e portando devem ser evitadas. A simples adoção de medidas paliativas e repressoras a exemplo de imposição de indenizações é ineficiente e incompatível com os recursos da Sociedade da Informação. No primeiro caso, porque o autor da coleta e divulgação pode não possuir patrimônio para satisfazer a indenização. No segundo, porque uma vez disponibilizada a obra em ambientes de informática e telecomunicações como a Internet, será praticamente impossível sua remoção completa posterior, como ocorreu no caso da biografia não autorizada do cantor Roberto Carlos que, apesar de ter obtido decisão judicial que mandara recolher todas as obras, o conteúdo pode ser encontrado livremente na Internet ${ }^{48}$.

Com efeito, o único meio eficaz de se evitar a ocorrência de danos à privacidade dos indivíduos que não autorizam a visibilidade de suas vidas na Sociedade da Informação é atuando preventivamente, de modo a evitar que ocorra a primeira divulgação.

E nesse passo, em se tratando de informações circuláveis na Internet, no cenário jurídico brasileiro tem relevância a Lei 12.965/2014, chamada de Marco Civil da Internet, que em se bojo trouxe regramentos sobre a coleta, armazenamento, transmissão e alguma tutela às informações pessoais, mas estabelecendo que a liberdade de expressão é fundamento da disciplina do uso da Internet (art. $2^{\circ}$, caput) e condição para o pleno exercício do direito de acesso (art. $6^{\circ}$ ), preocupando-se ainda com o impedimento à censura (art. 19).

A atenção conferida pela norma em tela à proteção das informações pessoais é evidenciada logo ao dispor sobre os princípios regentes dos usos e operações na Internet, quando destaca a garantia da liberdade de expressão (art. $\left.3^{\circ}, I\right)$, a proteção da privacidade (art. $3^{\circ}$, II), a proteção dos dados pessoais (art. $3^{\circ}, \mathrm{III}$ ), a inviolabilidade da intimidade e vida privada (art. $7^{\circ}, \mathrm{I}$ ), a inviolabilidade e sigilo do fluxo das comunicações (art. $7^{\circ}, \mathrm{II}$ ) e a inviolabilidade e sigilo das comunicações privadas armazenadas (art. $7^{\circ}$, III).

\footnotetext{
${ }^{47}$ RODOTÀ, Idem, p. 36.

48 "Mas logo depois de a Justiça mandar recolher a biografia do rei, o seu conteúdo caiu na rede. O livro pode ser acessado na íntegra num site chamado PDL - Projeto Democratização da Leitura. Lá existe até um fórum para discutir a obra" (CONSULTOR JURÍDICO, 2009).
} 
E é interessante notar, ainda, que de certa maneira o direito ao esquecimento $^{49}$ foi acolhido pelo Marco Civil da Internet quando em seu art. $7^{\circ}, \mathrm{X}$, previu a possibilidade de exclusão definitiva dos dados pessoais fornecidos para a criação e execução de uma determinada aplicação na internet, quando encerrada a relação este as partes envolvidas. Entretanto, esta exclusão não é automática, e dependerá do requerimento expresso do titular dos dados.

\section{CONSIDERAÇÕES FINAIS}

A investigação dos direitos à privacidade e à liberdade de expressão permite alocá-los como direitos humanos, presente na maioria dos instrumentos internacionais tendentes a definir e assegurar direitos humanos. Além disso, constata-se que foram incorporados pela ordem constitucional brasileira, por força da inclusão no rol dos direitos e garantias individuais da Constituição Federal de 1988, também da brasileira, o que Ihes confere status de direito fundamental.

$\mathrm{Na}$ Sociedade da Informação estes direitos recebem novos influxos e não raras vezes são postos em tensão e linha de colisão, na medida em que tecnologias de informática e comunicação cada vez mais invasivas facilitam a captação de informações, a criação inventiva e divulgação destas criações, tornando difícil ao indivíduo pôr-se em completo refúgio e solidão.

O aspecto crucial que se sobressai, na Sociedade da Informação, em virtude das técnicas e tecnologias de informática e comunicação, e que confere novos graus às expressões e atuações da liberdade de manifestação e à privacidade, consiste no reconhecimento de que inexiste uma única, ou poucas, fontes geradoras de informação, pois qualquer indivíduo é uma fonte com possibilidade de captar, produzir, conservar e disseminar informações, manifestações, opiniões, e cada receptor destas informações torna-se outro indivíduo com as mesmas habilidades e capacidades de manipulação da informação recebida e sua reprodução para outras pessoas, aumentando o universo de pessoas a quem levar o conhecimento. Com efeito, a capacidade de memória de informação, e sua distribuição, torna a defesa da privacidade bastante árdua diante da abertura às facilidades de divulgação e manifestação de opiniões, pensamentos e criação artística.

A análise de casos concretos feitas neste estudo, em especial a exposição de fotografias "The Neighbors" (os vizinhos) nos EUA, e a publicação de biografias não autorizadas no Brasil, evidenciaram o risco à privacidade refletida na exposição indevida da imagem das pessoas sob o pretexto de se tratar de

\footnotetext{
${ }^{49} \mathrm{O}$ direito ao esquecimento confere ao indivíduo a possibilidade de não ter os fatos de sua vida eternizados e passíveis de reavivamento a qualquer momento, sobretudo pela ação de tecnologias de informática e comunicação. No Brasil é reconhecido como uma particularidade da dignidade da pessoa humana, conforme entendimento cristalizado em março/2013 pelo Enunciado $\mathrm{n}^{\circ} 531$, CJF: "A tutela da dignidade da pessoa humana na sociedade da informação inclui o direito ao esquecimento".
} 
expressão artística e cultural, com inescondível violação da privacidade por tornarem públicos aspectos da vida particular dos indivíduos a que se referiram tais expressões de pensamento e criação.

Casos como os analisados se compatibilizam com os influxos da Sociedade da Informação que têm levado estudiosos de renome a defenderem que a privacidade se deslocou do seu viés negativo refletido na fórmula do direito de ser deixado em paz, para um estado ativo consistente num direito de controlar o uso das informações a respeito das pessoas. Assim, o indivíduo deve ter a possibilidade de acessar dados a seu respeito, retificá-los e inclusive obter seu cancelamento. Esta conotação ativa da privacidade atua evidentemente em face da liberdade de expressão, conferindo direito ao cidadão de conhecer o que sobre si venha ser divulgado, requerer a correção de informações inadequadas ou equivocada, e até mesmo buscar a eliminação daquelas que possam expor agressiva e desnecessariamente sua vida privada.

Todavia, este não deve ser o único sentido emprestado à privacidade, sob risco de esvaziá-la. O sentido clássico da privacidade, do direito de estar só, de ser deixado em paz, de se por em um receptáculo de solidão e isolamento e impedir que terceiros captem aspectos particulares da vida pessoal e os devolvam sob a forma de criações artísticas, precisa ser retomado, pois a partir do momento quem há captura de dados não autorizada, já ocorre a violação da privacidade, e esta ofensa é que precisa ser impedida para preservar a carga de fundamentalidade deste direito, diante de um exercício abusivo de direito que amiúde ocorre com a liberdade de manifestação de pensamento e opinião e expressão artística.

Nesse contexto, o Marco Civil da Internet (Lei 12.965/2014) pode fornecer mecanismos importantes de tutela, pois a par do valor conferido à liberdade de expressão, assegura a proteção à privacidade e aos dados pessoais, e adota o direito ao esquecimento como ferramenta hábil à exclusão de informações indesejadas a pedido de seu titular.

\section{REFERÊNCIAS}

ALEXY, Robert. Teoria dos Direitos Fundamentais. Tradução: Virgílio Afonso da Silva. São Paulo: Malheiros, 2012.

BOBBIO, Norberto. A Era dos Direitos. Tradução de Carlos Nelson Coutinho. Rio de Janeiro: Elsevier, 2004.

BRASIL. Constituição (1988). Constituição Federal da República Federativa do Brasil: promulgada em 5 de outubro de 1988. Organização do texto: Alexandre de Moraes. 36. ed., São Paulo: Atlas, 2012. (Coleção Manuais de Legislação).

. Câmara dos Deputados. Projeto de Lei n 393/2011. Dispõe sobre a alteração do art. 20 da Lei $n^{\circ} 10.406$, de 10 de janeiro de 2002 - Código Civil, para ampliar a liberdade de expressão, informação e acesso à cultura. Disponível em: <http://www. camara.gov.br/proposicoesWeb/fichadetramitacao?idProposicao=49195 >. Acesso em: 06 jun. 2014.

. Lei no 10.406 de 10 de janeiro de 2002. Código Civil. Institui o Código Civil. Diário Oficial da União, Brasília, DF, 11 jan. 2002, Seção 1. 
. TJRJ, 2a Câmara Cível, Processo 0000823-11.1996.8.19.0001, Des. Sérgio Cavalieri Filho, j. 15.05.2002. Disponível em: <http://www.tjrj.jus.br>. Acesso em: 06 jun. 2014.

BRIGGS, Asa; BURKE, Peter. De Gutenberg a Internet: uma historia social de los medios de comunicación. Madrid: Santillana, 2002.

CASTELLS, Manuel. A Sociedade em Rede. A era da informação: economia, sociedade e cultura. Tradução de Roneide Venâncio Majer. 7. ed., São Paulo: Paz e Terra, 1999.

CONSTANT, Benjamin. Da Liberdade dos Antigos Comparada à dos Modernos. Revista Filosofia Política, $\mathrm{n}^{\circ}$ 2, 1985. Disponível em: <http://caosmose.net/candido/ unisinos/textos/benjamin.pdf>. Acesso em: 06 jun. 2014.

CONSULTOR JURÍDICO. TJ-RJ proíbe publicação de biografia de Roberto Carlos. Notícia, 10 mar. 2009. Disponível em: <http://www.conjur.com.br/2009-mar-10/ biografiaroberto-carlos-nao-publicada-decide-tj-rj >. Acesso em: 06 jun. 2014.

DECOL, René Daniel. Era da Informação: sociedade, mito e tecnologia. [s.I.]: Cebrap, 2005.

DONEDA, Danilo Cesar Maganhoto. Considerações Iniciais sobre Bancos de Dados Informatizados e o Direito à Privacidade. In: TEPEDINO, Gustavo (org.) Problemas de Direito Civil-constitucional. Rio de Janeiro: Renovar, 2000, p. 111-136.

. Da Privacidade à Proteção de Dados Pessoais. Rio de Janeiro: Renovar, 2006.

FARIAS, Edilson Pereira de. Liberdade de Expressão e Comunicação. São Paulo: Revista dos Tribunais, 2004.

. Colisão de Direitos: a honra, a intimidade, a vida privada e a imagem versus a liberdade de expressão e informação. 3. ed., Porto Alegre: Sérgio Antônio Fabris, 2008.

FERNÁNDEZ, Antonio Aguilera. La Libertad de Expresión del Ciudadano y la Libertad de Prensa o Información: possibilidade y limites constitucionales. Granada, ES: Comares, 1990.

FOLHA DE SÃO PAULO. Fotógrafo ganha na justiça o direito de exibir fotos íntimas de vizinhos em Nova York. Folha llustrada, 08 set. 2013. Disponível em: <http://www1. folha.uol.com.br/ilustrada/2013/09/1337626-fotografo-ganha-na-justica-o-direito-de-exibirfotos-intimas-de-vizinhos-em-nova-york.shtml>. Acesso em: 06 jun. 2014.

GUERRA, Sidney Cesar Silva. A Liberdade de Imprensa e o Direito à Imagem. 2. ed., Rio de Janeiro: Renovar, 2004.

LÉVY, Pierre. Cibercultura. São Paulo: 34, 1999. p. 193.

LOJKINE, Jean. A Revolução Informacional. Tradução de José Paulo Netto. 3. ed., São Paulo: Cortez, 2002.

MENDES, Gilmar; BRANCO, Paulo Gustavo Gonet. Curso de Direito Constitucional. 7. ed., São Paulo: Saraiva, 2011.

MEYER-PFLUG, Samantha Ribeiro. Liberdade de Expressão e Discurso do Ódio. São Paulo: Revista dos Tribunais, 2009.

MILL, John Stuart. Sobre la Liberdad. Madrid: Alianza Editorial, 2004.

MIRANDA, Jorge. Notas sobre Cultura, Constituição e Direitos Culturais. Coimbra: Almedina, 2006.

NEVES, Clarissa Baeta; SAMIOS, Eva Machado Barbosa (Orgs.) Niklas Luhmann: a nova teoria dos sistemas. Porto Alegre: UFRGS, Goethe-Institut/ICBA, 1997. 
RODOTÀ, Stefano. A Vida na Sociedade da vigilância: a privacidade hoje. Tradução: Danilo Doneda e Luciana Cabral Doneda. Rio de Janeiro: Renovar, 2008.

SARLET, Ingo Wolfgang. A Eficácia dos Direitos Fundamentais. 9. ed., Porto Alegre: Livraria do Advogado, 2008.

SCHIAVO, Marcio R.; MOREIRA, Eliesio N. Glossário Social. Rio de Janeiro: Comunicarte, 2005.

SCHREIBER, Anderson. Direitos da Personalidade. 2. ed., São Paulo: Atlas, 2013.

SILVA, José Afonso de. Curso de Direito Constitucional Positivo. 35. ed., São Paulo: Malheiros, 2012.

VIEIRA, Tatiana Malta. O Direito à Privacidade na Sociedade da Informação: efetividade desse direito fundamental diante dos avanços da tecnologia da informação. Porto Alegre: Sérgio Antônio Fabris, 2007. 